\title{
CONTROLLED COMPARISON OF TIANEPTINE, ALPRAZOLAM AND MIANSERIN IN THE TREATMENT OF ADJUSTMENT DISORDERS WITH ANXIETY AND DEPRESSION
}

Marc Ansseau ${ }^{1}$, Michel Bataille², Guy Briole ${ }^{3}$, André De Nayer ${ }^{4}$, Pierre André Fauchère ${ }^{5}$, François Ferrero $^{6}$, Claudine Mertens ${ }^{7}$, Renzo Realini' ${ }^{8}$, Philippe Rombaut ${ }^{9}$, André Vereecken ${ }^{9}$, Benoit Troisfontaines ${ }^{10}$, Myriam Van Moffaert ${ }^{11}$

${ }^{1}$ Department of Psychiatry and Medical Psychology, C.H. U. du Sart Tilman, B-4000 Liège, Belgium ; ${ }^{2}$ Clinique Notre-Dame, B-4681 Hermalle s/Argenteau, Belgium ;

${ }^{3}$ Centre d'Instruction des Armées du Val de Grâce, F-75230 Paris, France ;

${ }^{4}$ Clinique Sainte-Thérèse. B-6061 Montignies-sur-Sambre, Belgium ;

${ }^{5} \mathrm{CH}-1950$ Sion, Switzerland;

${ }^{6}$ Policlinique Psychiatrique Universitaire B, CH-1005 Lausanne. Switzerland ;

${ }^{7}$ Psychiatrische Centra Sleidinge, 8-9940 Evergem-Sleidinge, Belgium;

${ }^{8} \mathrm{CH}-6900$ Lugano, Switzerland;

${ }^{9}$ Psychiatrisch Ziekenhuis Sint Jan, B-9900 Eeklo, Belgium ;

${ }^{10}$ Clinique Saint-Vincent. B-4000 Rocourt, Belgium ;

${ }^{11}$ Psychiatrische Kliniek, Akademisch Ziekenhuis. 8-9000 Gent, Belgium

KEYWORDS: adjustment disorders; mixed anxiety/depressive disorder; tianeptine; mianserin; alprazolam; antidepressant drugs

\section{ABSTRACT}

A multicentre study compared tianeptine $(37.5 \mathrm{mg} /$ day), an original psychotropic compound characterized by both antidepressant and anxiolytic potentials, with a reference antidepressant, mianserin (60 mg/day) and a reference anxiolytic, alprazolam $(1.5 \mathrm{mg} /$ day), in the treatment of 152 patients fulfilling DSM-III-R criteria for adjustment disorder with mixed emotional features (anxiety and depression). The study used a double-blind parallel design over a 6-week period. Clinical assessments included the Clinical Global Impressions (CGI), the Montgomery and Asberg depression rating scale (MADRS), the Hamilton anxiety rating scale, a visual analogue scale, and the somatic scale of the system developed by the Association for the Methodology and Documentation in Psychiatry (AMDP). Results showed very similar improvement in the three treatment groups on all rating instruments. Moreover, the number of patients exhibiting adverse events did not differ among the three groups. Therefore, these results show similar antidepressant and anxiolytic activity for tianeptine, mianserin and alprazolam in patients suffering from adjustment disorder with mixed emotional features. These promising findings should however be confirmed in a placebo-controlled trial. 


\section{Introduction}

The essential feature of adjustment disorder is a maladaptive reaction to an identifiable psychosocial stressor, or stressors, that occurs within 3 months after onset of the stressor, and has persisted for no longer than 6 months (American Psychiatric Association, 1987). The maladaptive nature of the reaction is indicated either by impairment of occupational functioning or in usual social activities or relationships with others or by symptoms that are in excess of a normal and expectable reaction to the stressor (American Psychiatric Association, 1987). The disorder is apparently common. In a recent survey among psychiatric outpatients, 14.8 per cent exhibited adjustment disorder as main diagnosis (Samuelian et al., 1994). Among the nine subtypes of adjustment disorders defined in DSM-III-R, the most frequent ones appear to be with anxious mood, with depressed mood, with physical complaints, and with mixed emotional features (Samuelian et al., 1994). In the absence of adequate studies, the treatment of adjustment disorders is still an object of controversy. Psychotherapy is generally recommended; antidepressants as well as anxiolytics could be beneficial (Kaplan and Sadock, 1990).

Tianeptine is a novel antidepressant agent which unlike other agents, stimulates the uptake of serotonin (Ansseau, 1993; Wilde and Benfield, 1995). In controlled trials, tianeptine exhibited both antidepressant and anxiolytic activity (Wilde and Benfield, 1995).

In this context, the purpose of the present pilot study was to evaluate the efficacy of tianeptine in the treatment of adjustment disorders with mixed emotional features (anxiety and depression) in comparison to the antidepressant mianserin (Brogden et al., 1978) and to the anxiolytic benzodiazepine alprazolam (Jonas and Cohon, 1993). This preliminary study could shed some light on the usefulness of pharmacological agents in adjustment disorders.

Table 1. Baseline characteristics of the sample

\begin{tabular}{|c|c|c|c|c|}
\hline & $\begin{array}{c}\text { Tianeptine } \\
n=49\end{array}$ & $\begin{array}{c}\text { Mianserin } \\
\qquad n=52\end{array}$ & $\begin{array}{l}\text { Alprazolam } \\
\qquad n=51\end{array}$ & $P$ \\
\hline Age & $43.6 \pm 10.7$ & $42.8 \pm 12.6$ & $44.2 \pm 11.1$ & 0.82 \\
\hline Gender (F/M) & $32 / 17$ & $37 / 15$ & $36 / 15$ & 0.82 \\
\hline $\begin{array}{l}\text { Onset of present stress } \\
\text { (days) }\end{array}$ & $95.9 \pm 118.2$ & $86.9 \pm 51.4$ & $118.8 \pm 252.3$ & 0.59 \\
\hline $\begin{array}{l}\text { Duration of present episode } \\
\text { (days) }\end{array}$ & $62.5 \pm 40.2$ & $66.2 \pm 45.1$ & $60.7 \pm 36.6$ & 0.78 \\
\hline MADRS & $27.0 \pm 7.3$ & $28.4 \pm 6.7$ & $27.5 \pm 5.5$ & 0.54 \\
\hline HARS & $27.0 \pm 5.7$ & $27.7 \pm 5.8$ & $28.1 \pm 5.9$ & 0.64 \\
\hline CGI 1 (severity of illness) & $4.1 \pm 0.7$ & $4.2 \pm 0.7$ & $4.2 \pm 0.6$ & 0.62 \\
\hline
\end{tabular}




\section{Methods}

\section{DESIGN OF THE STUDY}

The study was performed between September 1992 and March 1994 in seven Belgian, three Swiss, and one French centres used to collaborating and exhibiting good reliability in clinical rating (see affiliations). The trial used a double-blind design with three parallel groups of patients randomly assigned to tianeptine $(37.5 \mathrm{mg} /$ day $)$, mianserin $(60 \mathrm{mg} / \mathrm{day})$, or alprazolam (1.5 mg/day). After an optional run-in period of 7 days on placebo (3/day), the patients received ascending doses of active compounds during the first 3 days (tianeptine 12.5, 25, and $37.5 \mathrm{mg}$; mianserin 20, 40, and $60 \mathrm{mg}$; and alprazolam 0.5, 1, and $1.5 \mathrm{mg}$ ). All active compounds were then administered in three daily intakes. The duration of the study was 6 weeks. The daily dose was kept stable during the initial 2-week treatment period and could then be adapted according to efficacy and tolerability between 25 and $50 \mathrm{mg} /$ day for tianeptine, between 40 and 80 $\mathrm{mg} /$ day for mianserin, and between 1 and $2 \mathrm{mg} /$ day for alprazolam. No other psychotropic drugs were permitted throughout the study period. The trial was monitored according to all principles of European and US 'Good clinical practice' (CPMP Working Party on Efficacy of Medicinal Products, 1990; Mathieu, 1990).

\section{SUBJECTS}

A total of 152 outpatients were included in the study: 49 in the tianeptine group, 52 in the mianserin group, and 51 in the alprazolam group. Patients were 47 males and 105 females, aged 19-73 years, with a mean age (SD) of 43.5 (11.5) years. All subjects fulfilled DSM-III-R diagnostic criteria for adjustment disorder with mixed emotional feature (anxiety and depression) (DSMIII-R 309.28, American Psychiatric Association, 1987). In addition, the patients had total scores on Raskin depression and Covi anxiety scales of at least 7 with differences between the two scores less than 4 (Raskin et al., 1967; Covi et al., 1979). Patients presenting serious or uncontrolled medical illness were excluded from the study. The demographic and clinical characteristics of the patients are presented in Table 1 . No statistically significant differences existed among the treatment groups.

Finally, the protocol obtained approvals from the ethical committees of the various centres and all patients were fully informed of the purpose of the study and gave their consent.

\section{ASSESSMENTS}

Assessments were performed at baseline and after 1, 2, 4, and 6 weeks and included clinical global impressions (CGI) (Guy, 1976), the Montgomery and Asberg depression rating scale (MAPRS) (Montgomery and Asberg, 1979), the Hamilton anxiety rating scale (Hamilton, 1959), a global self-rated visual analogue scale, and the somatic scale of the systems developed by the Association for Methodology and Documentation in Psychiatry (Bobon et al., 1983). Physical examinations, including blood pressure, heart rate, and weight were performed at baseline as 
well as after 2, 4, and 6 weeks; EKG's and laboratory parameters were controlled at baseline and 6 weeks later.

\section{DATA ANALYSIS}

Initially, the homogeneity of the three treatment groups was controlled, using one-way analysis of variance or Fisher's exact test. All changes over time in ratings were completed by two-way analyses of variance (ANOVAs) with repeated measures and final scores were compared using one-way ANOVAs. All analyses used intent-to-treat samples with last observation carried forward as well as complete samples, but since the conclusions of this second analysis were similar, they will not be reported in this article. The number of treatment responders, defined by a decrease of initial scores of at least 50 per cent was compared using Fisher's exact test. Results are presented as means and standard deviations.

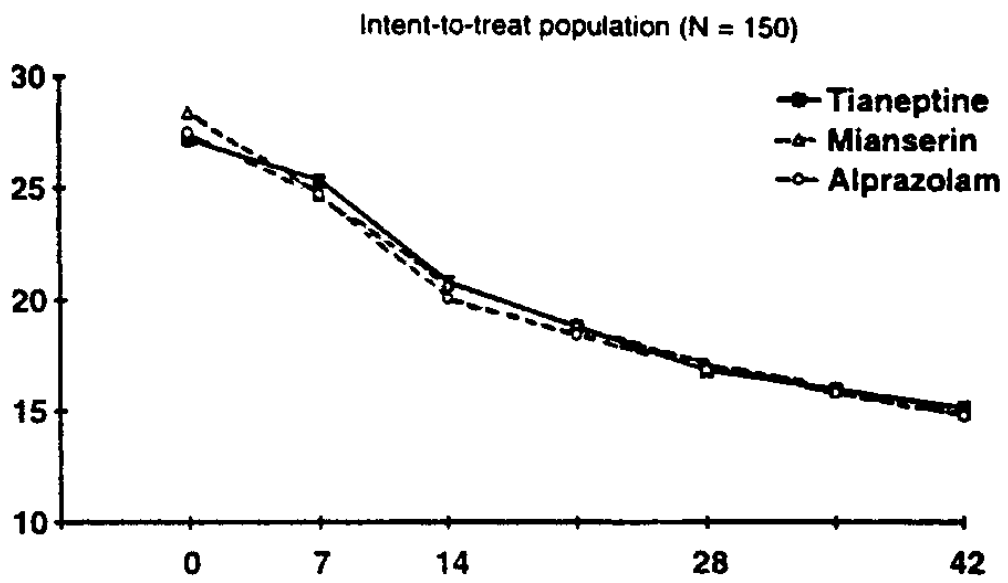

Figure 1. Changes over time in mean scores $( \pm S D)$ on the MADRS among patients treated by tianeptine, mianserin, or alprazolam

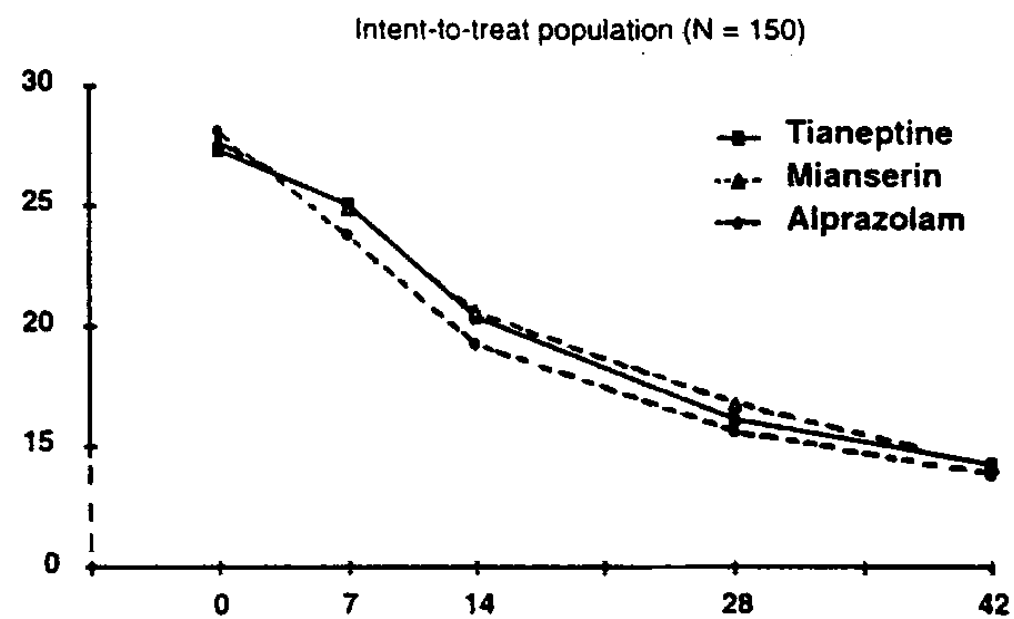

Figure 2. Changes over time in mean scores $( \pm$ SD) on the Hamilton anxiety rating scale among patients treated by tianeptine, mianserin, or alprazolam 


\section{Results}

\section{DROPOUTS}

A total of 33 patients (21.7 per cent) did not complete the study. Their distribution and main reasons are presented in Table 2 .

Table 2. Distribution of reasons for premature withdrawal

\begin{tabular}{lcccc}
\hline & Tianeptine & Mianserin & Alprazolam & $P$ \\
\hline Adverse event $(n=12)$ & 1 & 8 & 3 & 0 \\
$\begin{array}{l}\text { Major protocol violation } \\
(n=2)\end{array}$ & 1 & 1 & 5 & 0.08 \\
$\begin{array}{l}\text { Lack of efficacy } \\
(n=12)\end{array}$ & 4 & 3 & 2 & \\
$\begin{array}{l}\text { Known cause unrelated } \\
\text { to treatment } \\
(n=3)\end{array}$ & 1 & 0 & & \\
$\begin{array}{l}\text { Lost to follow-up } \\
(n=2)\end{array}$ & 1 & 0 & 0 & \\
Recovery $(n=2)$ & 2 & 0 & 11 \\
Total & 10 & 12 & & \\
\hline
\end{tabular}

\section{EFFICACY}

MADRS. MADRS total scores did not exhibit any significant differences among the three groups in their changes over time ( $p=0.92)$ (Figure 1$)$ as well as in their final scores: $15.2 \pm 9-3$ with tianeptine, $14.9 \pm 10.3$ with mianserin, and $14.8 \pm 10.3$ with alprazolam $(p=0.98)$. In addition, the analysis of individual items of the MADRS did not reveal any significant difference among the treatment groups.

The number of treatment responders did not differ among the three groups: 464 per cent with tianeptine, 50.0 per cent with mianserin, and 51.0 per cent with alprazolam (n.s.).

Hamilton anxiety rating scale. Hamilton total scores did not exhibit any significant differences among the three groups in their changes over time $(p=0.80)$ (Figure 2$)$ as well as in their final scores: $14.3 \pm 9.3$ with tianeptine, $14.2 \pm 10.5$ with mianserin, and $13.8 \pm 11.1$ with alprazolam ( $p=0.97$. In addition, the analysis of psychic and somatic anxiety subscores as well as individual items of the Hamilton anxiety rating scale did not reveal any significant difference among the treatment groups.

CGI. Final CGI scores did not differ among the three treatment groups: for CGI-1 (severity of illness), $2.4 \pm 1.4$ for tianeptine, $2.5 \pm 1.5$ for mianserin, and $2.2 \pm 1.6$ for alprazolam $(p=0.68)$; 
for CGI-2 (global improvement), respectively $1.5 \pm 1.2,1.6 \pm 1.3$, and $1.4 \pm 1.3(p=0.57)$; and for CGI-3 (efficacy index), respectively $2.5 \pm 1.1,2.2 \pm 1.3$, and $2.4 \pm 1.3(p=0.31$ ).

Visual analogue scale. Self-rated visual analogue scales did not exhibit any significant difference among the three groups in their changes over time $(p=0.82)$ as well as in their final scores: 5.8 \pm 2.8 with tianeptine, $5.5 \pm 2.9$ with mianserin, and $5.9 \pm 3.1$ with alprazolam $(p=0.83)$.

\section{SAFETY}

The number of patients exhibiting adverse events during the study period did not differ significantly among the three groups: 14 patients with tianeptine, 23 with mianserin, and 20 with alprazolam $(p=0.25)$. The distribution of individual adverse events is presented in Table 3.

Vital signs and laboratory parameters did not exhibit any significant modifications.

Table 3. Comparison of adverse events

\begin{tabular}{lccccccc}
\hline & \multicolumn{2}{c}{ Tianeptine $(n=49)$} & \multicolumn{3}{c}{ Mianserin $(n=52)$} & \multicolumn{3}{c}{ Alprazolam $(n=51)$} & $P$ \\
& $N$ & $\%$ & $N$ & $\%$ & $N$ & $\%$ & \\
\hline Dizziness & 1 & 2.0 & 3 & 5.8 & 1 & 2. & 0.62 \\
Headache & 3 & 6.1 & 3 & 5.8 & 3 & 5.9 & 1.00 \\
Appetite increase & 0 & 0 & 4 & 7.7 & 1 & 2.0 & 0.13 \\
Somnolence & 4 & 8.2 & 4 & 7.7 & 4 & 7.8 & 1.00 \\
Constipation & 0 & 0 & 4 & 7.7 & 1 & 2.0 & 0.13 \\
Nausea & 4 & 8.2 & 3 & 5.8 & 2 & 3.9 & 0.64 \\
Fatigue & 1 & 2.0 & 4 & 7.7 & 5 & 9.8 & 0.32 \\
\hline
\end{tabular}

\section{Discussion}

The results of the present study support similar efficacy and tolerability for tianeptine, mianserin, and alprazolam in patients suffering from adjustment disorder with mixed emotional features. The lack of significant differences between the treatments appears both for the depressive symptomatology, as measured by the MADRS, and the anxious symptomatology, as measured by the Hamilton anxiety rating scale. Moreover, the global assessments completed by the clinician (CGI) as well as by the patient him/herself (visual analogue scale) support the equivalence in efficacy among the three drugs.

Regarding safety, the number and the severity of side-effects did not significantly differ between tianeptine, mianserin and alprazolam. 
It is interesting to note that in this particular indication, antidepressants such as tianeptine and mianserin exhibit similar efficacy compared to a benzodiazepine anxiolytic, such as alprazolam. Tianeptine presents a particular profile which could theoretically make it a drug of choice in adjustment disorders with both depression and anxiety. First, animal models have shown that tianeptine reduces the hypothalamic-pituitary-adrenal (HPA) response to stress, antagonizes stress-induced behavioural deficits and prevents stress-induced dentritic atrophy (Delbende et al., 1991; Broqua et al., 1992; Fontanges et al., 1993; McEwan et al., 1993). Adjustment disorder can be interpreted as a pathological response to stress (American Psychiatric Association, 1987). Second, tianeptine has demonstrated a particular efficacy in anxious depression (Guelfi $e t$ al., 1989).

The coexistence of anxiety and depression is common and frequently poses treatment challenges in the clinical setting. Mixed anxiety-depressive disorder has been added in ICD-10 (World Health Organization, 1992) and as an appendix in DSM-IV (American Psychiatric Association, 1994). Mixed anxiety-depressive disorder is suggested to have a prevalence of between 1 per cent and 10 per cent (Wittchen and Essau, 1993) and seems to be most highly represented in the primary care patient population. A recent study in a primary-care clinic found that 19-2 per cent of patients had a comorbid anxiety and depressive disorder and 12-8 per cent a mixed anxietydepressive disorder (Stein et al., 1995). The optimal treatment for this mixed disorder is still to be defined (Zajecka and Ross, 1995) and due to its particular profile, tianeptine could represent a drug of choice.

The results of the present study should however be considered as preliminary due to the lack of a placebo group. Indeed, little is known about the natural evolution of adjustment disorder and the improvement noted in our trial could simply correspond to a spontaneous evolution. Therefore, a placebo-controlled trial is clearly needed in order to place tianeptine more precisely in the treatment of adjustment disorder with mixed emotional features.

\section{Acknowledgements}

The authors would like to thank Drs E. Devanthéry, M. Devanthéry-Axelrod, J. N. Desplands, R. Mascetti, M. Vianello and P. Papart who participated in the study. The study was supported by a grant from the 'Institut de Recherches Internationales Servier'. 


\section{References}

American Psychiatric Association (1987). Diagnostic and Statistical Manual of Mental Disorders, 3rd edn revised, (DSM-III-R). American Psychiatric Press, Washington, DC.

American Psychiatric Association (1994). Diagnostic and Statistical Manual of Mental Disorders. Fourth Edition. American Psychiatric Press, Washington, DC.

Ansseau, M. (1993). The paradox of tianeptine. European Psychiatry, 8 (Suppl. 2), 89s-93s.

Bobon, D., Baumann, U., Angst, J., Helmchen, H. and Hippius, H. (Eds) (1983). The AMDP-System in Pharmacopsychiatry. Karger, Basel.

Brogden, R. N., Heel, R., Speight, T. M. and Avery, G. S. (1978). Mianserin: a review of its pharmacological properties and therapeutic efficacy in depressive illness. Drugs, 16, 273-301.

Broqua, P., Baudrie, V., Laude, D. and Chaouloff, F. (1992). Influence of the novel antidepressant tianeptine on neurochemical, neuroendocrinological, and behavioral effects of stress in rats. Biological Psychiatry, $31,391-400$.

Covi, L., Lipman, R., McNair, D. M. and Czerlinski, T. (1979). Symptomatic volunteers in multicenter drug trials. Progress in Neuropsychopharmacology, 3, 521-533.

CPMP Working Party on Efficacy of Medicinal Products (1990). EEC Note for Guidance: Good clinical practice for trials on medicinal products in the European Community. Pharmacology and Toxicology, 67, 361-372.

Delbende, C., Contesse, V. and Mocaër, E. (1991). The novel antidepressant, tianeptine, reduces stressevoked stimulation of the hypothalamo-pituitary-adrenal axis. European Journal of Pharmacology, 202, 391-396.

Fontanges, R., Mimouni, J., de Grieve, X., Picard, J., Pugeat, M. and Bange, C. (1993). Effect of tianeptine on neuroendocrine, enzyme and behavioral responses to restraint stress in male rats. European Psychiatry, 8 (Suppl. 2), 67s-73s.

Guelfi, J. D., Pichot, P. and Dreyfus, J. F. (1989). Efficacy of tianeptine in anxious-depressed patients: results of a controlled multicenter trial versus amitriptyline. Neuropsychobiology, 22, 41-48.

Guy, W. (Ed.) (1976). ECDEU Assessment Manual for Psychopharmacology, revised. National Institute of Mental Health, Psychopharmacology Research Branch, Rockville, MD.

Hamilton, M. (1959). The assessment of anxiety states by rating. British Journal of Medical Psychology, 32, 50-55.

Jonas, J. M. and Cohon, M. S. (1993). A comparison of the safety and efficacy of alprazolam versus other agents in the treatment of anxiety, panic, and depression: a review of the literature. Journal of Clinical Psychiatry, 54 (Suppl.) 25-45.

Kaplan, H. I. and Sadock, B. J. (Eds) (1990). Pocket Handbook of Clinical Psychiatry. Williams and Wilkins, Baltimore.

Mathieu, M. (1990). New Drug Development: a Regulatory Overview. Parexel, Cambridge, MA.

McEwen, B. S., Angulo, J., Gould, E., Mendelson, S. and Watanabe, Y. (1993). Antidepressant modulation of isolation and restraint stress effects on brain chemistry and morphology. European Psychiatry, 8 (Suppl. 2), 41s-48s. 
Montgomery, M. and Asberg, M. (1979). A new depression scale designed to be sensitive to change. British Journal of Psychiatry, 134, 382-389.

Raskin, A., Schulterbrandt, J., Reatig, N. and Rice, C. E. (1967). Factors of psychopathology in interview, ward behavior and self-report ratings of hospitalized depressions. Journal of Consulting Psychology, 31, 270-278.

Samuelian, J. C., Charlot, V., Derynck, F., Rouillon, F. and G. E. P. (1994). Troubles de I'adaptation: à propos d'une enquête épidémiologique. Encéphale, 20, 755-765.

Stein, M. B., Kirk, P., Prabhu, V., Grott, M. and Terepa, M. (1995). Mixed anxiety-depression in a primarycare clinic. Journal of Affective Disorders, 34, 79-84.

Wilde, M. I. and Benfield, P. (1995). Tianeptine: review of its pharmacodynamic and pharmacokinetic properties, and therapeutic efficacy in depression and coexisting anxiety and depression. Drugs, 49, 411439.

Wittchen, H. U. and Essau, C. A. (1993). Comorbidity and mixed anxiety-depressive disorders: is there epidemiologic evidence? Journal of Clinical Psychiatry, 54 (Suppl. 1), 9-15.

World Health Organization (1992). International Classification of Diseases, 10th edn. American Psychiatric Press, Washington, DC.

Zajecka, J. M. and Ross, J. S. (1995). Management of comorbid anxiety and depression. Journal of Clinical Psychiatry, 56 (Suppl. 2), 10-13. 